\title{
ENSINO DE EMPREENDEDORISMO POR PROJETO INTERDISCIPLINAR NA GRADUAÇÃO
}

Geani Moller Cavallaro ${ }^{1}$

Patricia Viveiros De Castro Krakauer ${ }^{2}$

\footnotetext{
${ }^{1}$ Faculdade Metrocamp - Grupo IBMEC

${ }^{2}$ FACCAMP Faculdade Campo Limpo Paulista
} 


\section{ENSINO DE EMPREENDEDORISMO POR PROJETO INTERDISCIPLINAR NA GRADUAÇÃO}

\section{Resumo:}

O presente estudo tem como objetivo apresentar um processo para se ensinar empreendedorismo por projetos interdisciplinares que possa ser aplicado por docentes na graduação. Trata-se, portanto, de uma pesquisa de natureza aplicada, exploratória e qualitativa. A partir da revisão teórica acerca do ensino de empreendedorismo, do ensino por projeto e interdisciplinar, emergiu a construção da proposta, sustentada pelos conceitos teóricos de William Kilpatrick e Hilton Japiassu. Tal processo foi submetido a análise de especialistas por meio de entrevista com técnica projetiva. Os principais resultados demonstraram uma aceitação do modelo interdisciplinar de ensino, revelando a necessidade de se ter um olhar prático para a disciplina de empreendedorismo. A pesquisa contribuiu com docentes que buscam alternativas para o ensino de empreendedorismo considerando uma perspectiva interdisciplinar e prática, podendo ser o processo desenvolvido aplicado em instituições de ensino superior que almejem ensinar empreendedorismo na graduação.

Palavras-Chave: Ensino de empreendedorismo. Ensino por projeto. Interdisciplinaridade. 


\section{Introdução}

O empreendedorismo tem um poder transformador sobre as pessoas, sobre a comunidade e o país. Viabiliza a concretização de sonhos. O empreendedorismo transpõe barreiras sociais e econômicas. Um país que acredita e investe em uma educação voltada ao empreendedorismo está suplantando o desenvolvimento para muitas gerações.

Apesar da importância do tema para a realidade do nosso país, ainda hoje no Brasil, apesar dos avanços ocorridos, existem fatores limitantes ao empreendedorismo, entre eles, a educação (WRIGHT; SILVA; SPERS, 2010). Muito embora o ensino de empreendedorismo seja uma realidade nas universidades, em especial nos cursos de administração, acredita-se que as instituições de ensino superior no Brasil ainda direcionam seu foco na formação de profissionais para o mercado, são poucas as que estimulam o aluno para o empreendedorismo, mesmo quando se considera a concepção de empreendedorismo voltada à abertura de novos negócios, como no senso comum. Culturalmente, a sociedade brasileira tende a dar maior ênfase a uma formação acadêmica voltada a conquista de um emprego formal, focada em grandes organizações e sem preparar o discente para um mundo flexível e sem possibilitar um pensar holístico, necessário nos dias atuais (LAVIERI, 2010).

Uma das formas de se buscar um pensamento holístico, flexível e inovador é através da educação empreendedora percebida como método (NECK; GREENE, 2011; SARASVATHY; VENKATARAMAN, 2011), possível de ser aplicado em instituições de ensino (KRAKAUER, 2016). Inclusive, a pesquisa realizada pela ENDEAVOR e SEBRAE (2014) evidencia a importância das universidades públicas e privadas na contribuição para um ambiente de estímulo ao empreendedorismo, aumento da confiança e inovação, bem como preparar o aluno para enfrentar os desafios de empreender a fim de desenvolver empreendimentos sólidos, com potencial de crescimento.

Contudo, apesar de possível e da proliferação de cursos, do número de alunos, da infraestrutura relacional - no que diz respeito a centros de empreendedorismo, escolas e afins - e das publicações, a diversidade de métodos e a dificuldade de validação destes são fatores limitantes ao exercício da docência na área de empreendedorismo (KATZ, 2003).

Salusse e Andreassi (2016) observam que, mesmo havendo uma grande diversidade de metodologias possíveis, o que deveria se almejar ao se ensinar empreendedorismo é a realidade da atividade empreendedora, em que a prática é privilegiada, uma vez que permite ao aluno desenvolver habilidades necessárias ao empreendedorismo, em relação às metodologias tradicionais de ensino. Uma das possibilidades apontadas no relatório da pesquisa de Krakauer (2016) é a utilização de projetos interdisciplinares, apontada visto essa ter sido uma das opções mais lembradas pelos respondentes quando questionados sobre didáticas possíveis para se ensinar a temática, carecendo, contudo de estudos futuros.

De acordo com Japiassu (1976) o ensino interdisciplinar é um passo importante para o desenvolvimento de uma educação mais holística e uma modalidade possível dentro das universidades. De acordo com Teixeira (2007), a atividade interdisciplinar não é fruto nem do

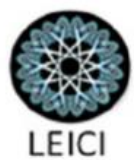


sujeito nem do objeto, mas sim dos aspectos processuais da atividade per si. Isso não significa a eliminação da ciência e das disciplinas, mas sim uma estratégia de flexibilização e integração.

Uma das possibilidades para se trabalhar a interdisciplinaridade é o ensino por projetos, visto que prática por meio do desenvolvimento de projetos possibilita o envolvimento do aluno, do professor, dos recursos disponíveis e inclusive das novas tecnologias, fomentando a interação no ambiente de aprendizagem. Torna-se, assim, um ambiente fértil para a autonomia do aluno e construção do conhecimento em distintas áreas do saber, uma vez que cabe a ele a busca de informações que sejam significativas para a compreensão, representação e resolução de uma situação-problema (CATTAI; PENTEADO, 2009).

Partindo, dessa forma, da sugestão de estudos futuros apontados por Krakauer (2016) e também dado os resultados obtidos com levantamento bibliográfico realizado em outubro/2016 nas bases de dados SPELL e EBSCO: ao se utilizar as palavras-chave Education, Entrepreneurship, interdisciplinary, Project com o operador booliano AND, e as respectivas palavras também em português, foram encontrados três trabalhos que atendessem a busca (CIOBOTARU, 2013; SILVA et al., 2009; VANEVENHOVEN, 2013), mostrando ser um tema passível de investigação exploratória. O conteúdo de tais estudos será apresentado na seção 3.

Acredita-se, assim, que o ensino de empreendedorismo possa ser interdisciplinar, sendo o ensino através de projeto uma das possibilidades. Dada a necessidade de se explorar tal temática dentro do contexto apresentado, a atual pesquisa buscará responder: Como utilizar o método de projetos interdisciplinares no processo de ensino de empreendedorismo na graduação?

Possui como objetivo a apresentação de um processo para se ensinar empreendedorismo por projetos interdisciplinares que possa ser aplicado por docentes e instituições de ensino, sendo essa a contribuição do presente artigo.

\section{Método}

A pesquisa científica se caracteriza pela busca por conhecimentos apoiada em procedimentos que gerem resultados confiáveis. A origem deste processo pode se dar por dificuldades de prática profissional ou ainda pelo interesse de investigação de determinados fenômenos. A natureza da pesquisa pode ser classificada em pesquisa básica e pesquisa aplicada, tendo a primeira o objetivo gerar conhecimentos novos e úteis, que promovam avanço na ciência e a segunda tem como objetivo a aplicação prática direcionada à solução de problema específico envolvendo verdades e interesses locais (PRODANOV; FREITAS, 2013).

Dessa forma, o presente estudo é uma pesquisa de natureza aplicada, pois estrutura-se na experiência prática das pesquisadoras que perceberam uma lacuna de natureza prática para a investigação corrente. Trata-se de um estudo exploratório por abraçar uma temática pouco explorada de difícil formalização de hipóteses precisas (GIL, 2010) dada a falta de convergência empírica de estudos anteriores (NECK; GREENE, 2011; VANEVENHOVEN, 2013). Por ser exploratório, optou-se por uma abordagem qualitativa, buscando maior profundidade nas discussões propostas, envolvendo uma interpretação do fenômeno (DENZIN; LINCOLN, 2006) na qual o pesquisador é "ao mesmo tempo sujeito e objeto de sua pesquisa" (GIL, 2010, p.32).
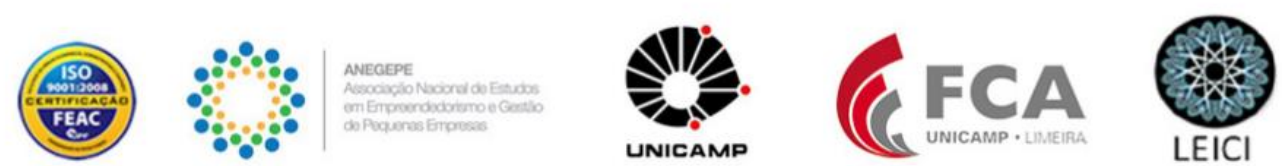
A estruturação da pesquisa se deu em duas etapas: (1) Levantamento de dados bibliográficos, e (2) entrevista em profundidade, semiestruturada com especialistas. Na primeira etapa buscou-se fundamentos teóricos para a elaboração de uma proposta de processo para o ensino de empreendedorismo por projeto interdisciplinar e na segunda etapa buscou-se discutir a proposta com especialistas, considerados neste estudo como docentes de empreendedorismo, de forma a consolidar a proposta do processo em questão.

Na etapa 1, a coleta de dados ocorreu seguindo os passos preconizados por Cronin, Ryan e Coughlan (2008) para a pesquisa bibliográfica sistemática: (1) seleção dos tópicos a serem investigados, (2) busca da literatura, (3) seleção dos textos, leitura e análise. Destaca-se que para conhecer o estado da arte da temática em estudo, foi realizado um levantamento preliminar nas bases SPELL e EBSCO, conforme mencionado na seção introdutória. Como a interseção dos temas só identificou três artigos nessas bases, foi feito então o levantamento com as temáticas isoladas, buscando modelos que pudessem fundamentar teoricamente a pesquisa. Tais resultados são apresentados na seção 3 e foram o alicerce para a construção da proposta apresentada na seção 4 , base para a investigação de campo subsequente.

$\mathrm{Na}$ etapa 2 a coleta ocorreu em entrevistas em profundidade, semiestruturada com especialistas que utilizaram a técnica projetiva como procedimento. Os passos para a sua realização foram:

(1) Elaboração do roteiro da entrevista: a primeira parte do roteiro trazia perguntas sobre o perfil do respondente, que serão apresentados na seção 5; a segunda parte possuía 03 questões sobre a fase estabelecimento do propósito, seguida por 03 questões sobre o planejamento, mais 03 questões sobre a fase de execução e 05 questões sobre o julgamento e feedback.

(2) Pré-teste: O pré-teste foi realizado com dois docentes nos dias 27/04/2017 e 25/04/2017, sendo avaliado a sequência da entrevista, o entendimento das perguntas e o tempo para a realização da entrevista. Com o pré-teste foi inclusa uma questão no roteiro, por sugestão dos respondentes, sobre a viabilidade do processo.

(3) Seleção dos entrevistados: foi adotado como critério para a seleção dos entrevistados serem professores da graduação de empreendedorismo ou áreas correlatas (plano de negócios, inovação, criatividade).

(4) Elaboração de protocolo: para a realização da entrevista foi elaborado um protocolo para registro e transcrições da pesquisa.

(5) Envio de convite aos entrevistados: foram enviados 27 convites por email para professores selecionados em universidades de atuação das pesquisadoras. Mediante aceitação, foi feito $\mathrm{o}$ agendamento para a entrevista presencial e o preenchimento do consentimento livre e esclarecido, seguindo a ética de pesquisas qualitativas proposta por Creswell (2010).

(6) Realização da entrevista: Foram entrevistados 12 especialistas. As entrevistas ocorreram entre maio e junho/2017, foram presenciais e gravadas. Utilizou-se para a sua realização a técnica projetiva (FLICK, 2009). Para isso, forma desenvolvidos dois materiais de suporte às entrevistas: painel visual do processo e fichas das etapas do processo. As entrevistas seguiram os seguintes passos: (a) apresentação do painel visual do processo (veja Figura 1, que se encontra na seção 4), (b) apresentação e discussão das etapas que compõem cada

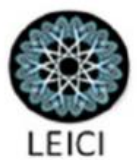


fase do processo mediante a apresentação das fichas sobre cada etapa, facilitando a visualização das mesmas pelo entrevistado e seguindo o roteiro elaborado, (c) transcrição das entrevistas e (d) análise dos dados, que será detalhada na sequência.

A análise dos dados das entrevistas foi feita através da análise de conteúdo e seguiu as três etapas propostas por Bardin (2009): pré-análise, exploração do material e tratamento dos resultados. Na primeira fase foram feitas todas as transcrições das entrevistas e selecionados os trechos de relevância, consolidados em categorias e unidades de contextos. Na fase seguinte ocorreu a consolidação das unidades de contextos em unidades de registro e na última fase ocorreu a tabulação dos dados, que serão apresentados na seção 5.

Foram considerados os preceitos éticos propostos por Creswell (2010), a saber: envio do consentimento livre e esclarecido, preocupação com a relevância e adequação da pesquisa ao respondente, garantidos a transparência de propósitos da pesquisa e o anonimato.

\section{Fundamentos teóricos}

\section{Ensino de Empreendedorismo}

De acordo com Filion (1999) é possível verificar nos estudos de Cantilon e Say a dificuldade em atribuir ao empreendedorismo como categoria de uma determinada disciplina, uma vez que ao se aprofundar no tema em disciplina específica, logo estariam excedendo os limites estabelecidos daquela área de conhecimento. Tal característica tira o empreendedorismo de uma relação direta e única com determinada área do conhecimento.

No Brasil, a educação empreendedora ocorreu mais tarde que nos Estados Unidos, em grande parte pela industrialização tardia e pela forte cultura do emprego. Foi somente a partir da década de 1980 que ganhou espaço no âmbito universitário, sendo o primeiro curso ministrado na faculdade de administração de empresas da Fundação Getúlio Vargas (SALUSSE; ANDREASSI, 2016).

Percebe-se, ao se consultar literatura pertinente (NECK; GREENE, 2011; VANEVENHOVEN, 2013; ZAMPIER; TAKAHASHI, 2011) que não existe um consenso sobre como se deve ensinar a temática, sendo que alguns modelos despontaram das pesquisas consultadas: o modelo defendido por Moraes e Hoeltgebaum (2003) que apresenta a aprendizagem por etapas assim como ciclo de vida da empresa, o modelo de Rae (2004) em que considera o indivíduo em seu contexto social e abarca três dimensões: a) formação pessoal e social; b) aprendizagem contextual; c) empreendimento negociado e o modelo de Politis (2005) cujo foco do estudo está no processo de transformação das experiências dos empreendedores.

Os três artigos levantados com a pesquisa realizada nas bases mencionadas na seção introdutória, específicos sobre a interseção das temáticas em estudo nesta pesquisa, mostram ser ainda incipiente o entendimento da possibilidade de se utilizar projetos interdisciplinares para o ensino do empreendedorismo. Silva et al. (2009) abordam um projeto isolado na instituição de ensino do Ceará e mencionam a necessidade de um método específico para o

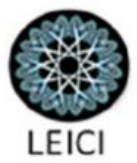


ensino de empreendedorismo, particularmente as participativas e alicerçadas no envolvimento ativo dos participantes. Discute o projeto Arquimedes que tem como objetivo a elaboração de um plano de ação para implementação de um negócio para geração de trabalho e renda para uma comunidade carente. Possuía, segundo esses autores, um caráter multidisciplinar.

Ciobotaru (2013) aborda a educação empreendedora por projeto, mas com âmbito empresarial, maneira pela qual o relacionamento acadêmico-mercado afeta a compreensão do significado genuíno da educação. Já o estudo de Vanevenhoven (2013) retrata resultados de sua pesquisa global e longitudinal sobre o impacto da educação empreendedora na vida dos estudantes e, muito embora seja um estudo profundo e de grande interesse, não tem o direcionamento pretendido com esta pesquisa. Contudo, esse autor aponta que existe uma demanda para mais estudos acerca da educação empreendedora, pois há pouco consenso sobre os métodos usados para ensinar empreendedorismo.

\section{Ensino por projetos}

Muito embora o tema seja adotado em alguns momentos como uma proposta inovadora na educação, ele não é recente e tão pouco a discussão sobre o ensino por projeto e suas práxis. Leite (2007) em sua dissertação de mestrado faz uma ampla pesquisa sobre o método de ensino por projeto e os principais pensadores. De acordo com essa autora, partindo das pesquisas realizadas nas obras de Knoll de 1997 e Boutinet de 2002, onde se relata a cronologia do método, os primeiros relatos são do século XVI nas escolas de arquitetura italianas, em que o projeto era usado como uma forma de diferenciá-los dos artesões da época, dando ao seu trabalho um caráter de criação e propriedade intelectual.

As primeiras obras acerca do método de projetos com uma abordagem pedagógica foram elaboradas por J. Dewey e W. H. Kilpatrick, entre os anos de 1915 e 1920, mas cabe ressaltar que este foi um período de formação com base no modelo fordista, cuja a preocupação era apenas a formação de mão de obra para o trabalho em uma fábrica, sem a preocupação em incorporar aspectos da realidade cotidiana dentro da escola. Neste sentido, as propostas apresentadas tanto por Dewey e como por Kilpatrick buscavam "formar os alunos para uma vivência democrática que exigia envolvimento e participação na aprendizagem" (BEHRENS, 2014, p.98).

A primeira publicação de Kilpatrick sobre o tema se deu em 1918, na obra The Project Method: The use of the purposeful act in the educational process. Segundo Garcia (2012) o método se diferenciava de outras estratégias de ensino e aprendizagem, pois o foco estava de resolução de problemas e na possibilidade dos alunos em aprenderem por meio de uma questão real e relevante. Outro aspecto positivo apresentado pelo autor está na possibilidade de trabalho em grupo, considerando o currículo, contudo levando em consideração sua experiência vivencial (LEITE, 2007).

De acordo com Terossi e Santana (2011), no Brasil, a discussão sobre projetos iniciouse na década de 1930, com a "pedagogia de projetos", proposta por Anísio Teixeira e Lourenço Filho, no contexto do movimento da Escola Nova. Sobre a Escola Nova, Vidal (2000) esclarece que sua construção se deu pela diferença instituída entre esta e a escola tradicional. A base da proposta era a criança como centro do processo de aprendizagem, pela observação e ação, que possibilite a elaboração do seu próprio saber.

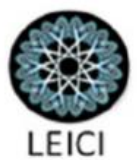


Os projetos na visão de Kilpatrick podem ser desenvolvidos individualmente e coletivamente, neste último, na visão do pesquisador com grande valor social. Kilpatrick propõe quatro tipos de projetos: (1) projetos que resultam necessariamente em um produto externo; (2) projetos que propiciam uma experiência estética; (3) projetos com propósito de solucionar problemas intelectuais; e (4) projetos direcionados à obtenção de um título.

O interessante do método para o ensino de empreendedorismo é a sua relação com a interdisciplinaridade (BEHRENS, 2006), buscando uma visão mais holística e flexível, aderente ao ensino dessa temática. De acordo com Garcia (2012, p. 217), "o método de projeto foi o precursor de uma nova abordagem de aprendizagem, baseada em atividades mais abertas e desenvolvidas de forma flexível, embora focalizadas em questões articuladas ao currículo". O autor evidencia ainda que mesmo após "décadas da proposição original do método de Kilpatrick, a abordagem de projetos persiste nas escolas como importante alternativa para o ensino interdisciplinar" (Garcia, 2012, p. 217).

Dessa forma, na presente pesquisa como fundamento teórico no que concerne o método de projetos, considerou-se o modelo de Kilpatrick, apresentado por Leite (2007), especificamente a proposta de projetos que resultam necessariamente em um produto externo, visto ser objetivo da educação empreendedora a similaridade com a prática empreendedora (SALUSSE; ANDREASSI, 2016). Essa proposta de projeto estabelece quatro etapas para sua aplicação: Estabelecimento de Propósito, Planejamento, Execução e Julgamento (LEITE, 2007).

No estabelecimento de propósito são determinados os elementos: equipe de gerenciamento, liderança e objetivos do projeto. No pilar de planejamento se estabelece o escopo do projeto. No pilar de execução estão todas as etapas inerentes a execução do projeto e as ações necessárias para que ela aconteça e finalmente no pilar julgamento/ feedback são identificadas as formas de avaliação e retorno aos alunos.

\section{Interdisciplinaridade no ensino}

O tema interdisciplinaridade foi trazido para o Brasil por Japiassu, em 1976, como resultados das discussões ocorridas no Congresso de Nice, na França, em 1969. Japiassu (1976) e Fazenda (1991) são os responsáveis por difundir o tema no Brasil: Japiassu pelo eixo temático epistemológico e Fazenda pelo eixo temático pedagógico. Ambos embasados pela filosofia do sujeito, diferente do paradigma tradicional de educação que valorizava o currículo centrado em disciplinas estanques.

Os conceitos de multidisciplinaridade, interdisciplinaridade e transdisciplinaridade se apresentam como um caminho de enriquecimento do pensamento em contraposição as barreiras da ciência clássica, fracionada e limitada dentro da sua área de saber. Na visão de Morin e Le Moige (2000) não é negar o papel exercido pela disciplinaridade, confrontando-a com a transdisciplinaridade, e sim, lançar mão de cada uma delas em conformidade com o problema a ser tratado.

$\mathrm{Na}$ visão de Morin (2007) tanto os conceitos multidisciplinares, interdisciplinares e transdisciplinares contribuem para o desenvolvimento do saber, mas nenhum se basta. $\mathrm{Na}$ concepção do autor a interdisciplinaridade junta disciplinas diferentes; a multidisciplinaridade

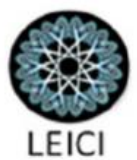


as articula; contudo apenas a transdisciplinaridade faz com que aportes diferentes trabalhem para o mesmo fim.

Pombo (2006) afirma que independente das conceituações a interdisciplinaridade existe como prática e está presente nas mais diversas atividades universitárias, seja na pesquisa (pura e aplicada), nos centros de investigação interdisciplinar, como polo organizador de novas ciências, entre outra. Na concepção da autora, o que de fato distingue a interdisciplinaridade "é a intensidade das trocas realizadas entre os cientistas especializados e o grau de integração real das disciplinas em torno de um determinado projeto de pesquisa" (POMBO, 2006, p. 225). Japiassu (1976) afirma ser possível ter um ensino interdisciplinar nas universidades e apresenta algumas vantagens: (1) proporciona trocas generalizadas de informações e de críticas; (2) amplia a formação geral de todos quantos se engajam na pesquisa científica especializada; (3) favorece a explicitação de postulados epistemológicos, (4) prepara melhor os indivíduos para a formação profissional, (5) prepara e engaja os especialistas na pesquisa em equipe e (6) assegura e desenvolve a educação permanente.

Esse autor propõe um modelo a que chama de "convergências metodológicas" e estabelece três tópicos: níveis do projeto interdisciplinar, etapas fundamentais do método e condições para realização. No que se refere aos níveis do projeto o autor apresenta dois níveis, nomeados por ele como nível da démarche pluridisciplinar e o nível da pesquisa interdisciplinar. O primeiro consiste no estudo de um fenômeno a partir de diferentes ângulos e o segundo "supõe uma integração real das disciplinas, podendo esta integração construir-se segundo dois estágios fundamentais: o dos conceitos e o dos métodos" (JAPIASSU,1976, p. 121).

Quanto ao enfoque metodológico Japiassu (1976) apresenta enfoques que denominou de nível prospectivo - cujo enfoque está na tarefa interdisciplinar - e o nível retrospectivo, com enfoque na reflexão interdisciplinar. Na concepção do autor o primeiro enfoque está relacionado à realidade concreta, com um objetivo de ordem prática, enquanto o segundo enfoque está relacionado a análise crítica dos saberes já constituídos, buscando a unidade do objeto do saber. O autor afirma ainda, que muito embora sejam distintos, são convergentes e complementares, uma vez que só há reflexão se houver conteúdo servindo de suporte.

A partir da discussão desses três tópicos, Japiassu (1976) propõe então o modelo, composto das seguintes etapas: Constituição da Equipe de Trabalho, Estabelecimento dos conceitos chaves comuns à pesquisa, Estabelecimento da problemática da pesquisa, Repartição das tarefas, análise e apresentação consolidada dos dados. Esse será o modelo utilizado na atual pesquisa no que concerne a transdisciplinaridade e cada etapa será explicada no Quadro 1, apresentado na seção 4.

\section{Proposta de processo de ensino de empreendedorismo por projeto interdisciplinar}

No levantamento bibliográfico realizado emergiram Kilpatrick (1929) como autor seminal para o ensino por projeto e Japiassu (1976) sobre a prática pedagógica interdisciplinar cujos fundamentos teóricos alicerçaram a elaboração de uma proposta para a utilização de projetos interdisciplinares no ensino de empreendedorismo.

Como mencionado na seção 3, optou-se pela perspectiva de projetos que resultam necessariamente em um produto externo e seus quatro pilares, a saber, estabelecimento de

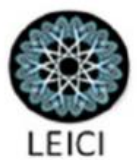


propósito, planejamento, execução e julgamento (KILPATRICK, 1929). As etapas metodológicas de trabalhos interdisciplinares propostas por Japiassu (1976), apresentadas no Quadro 1, foram observadas na construção do processo.

Quadro 1: Etapas do método proposto por Japiassu (1976).

\begin{tabular}{|c|c|c|}
\hline ETAPAS & AÇÃO & DIRETRIZES \\
\hline $1^{\text {a Etapa }}$ & $\begin{array}{l}\text { Constituição da } \\
\text { Equipe de } \\
\text { Trabalho }\end{array}$ & $\begin{array}{l}\text { A equipe deve estabelecer os limites da pesquisa por meio da organização e } \\
\text { regras metodológicas. Deve ainda não ser muito grande e não ter uma } \\
\text { liderança linear e sim adotar uma ordem concêntrica. A equipe não precisa } \\
\text { ficar presa às normas da instituição, podendo impor-se como uma } \\
\text { organização autônoma. A liderança não deve ser atribuída à pessoa, mas a } \\
\text { uma das disciplinas correntes. }\end{array}$ \\
\hline $2^{\mathbf{a}}$ Etapa & $\begin{array}{l}\text { Estabelecimento } \\
\text { dos conceitos } \\
\text { chaves da } \\
\text { comum à } \\
\text { pesquisa }\end{array}$ & $\begin{array}{l}\text { Deve ser promovida uma clarificação do vocabulário comum a ser utilizado } \\
\text { por todos a fim de minimizar os riscos da construção de um diálogo fundado } \\
\text { em preconceitos e mal-entendidos. O importante é que todos tenham a } \\
\text { mesma compreensão em relação à linguagem e conceitos. }\end{array}$ \\
\hline $\mathbf{3}^{\mathbf{a}}$ Etapa & $\begin{array}{l}\text { Estabelecimento } \\
\text { da problemática } \\
\text { da pesquisa }\end{array}$ & $\begin{array}{l}\text { A definição do conceito já significa formular um problema. Esta etapa se } \\
\text { configura como momento decisivo do método. }\end{array}$ \\
\hline $4^{\text {a Etapa }}$ & $\begin{array}{l}\text { Repartição das } \\
\quad \text { tarefas }\end{array}$ & $\begin{array}{l}\text { Determinação dos passos e responsabilidades de cada um na pesquisa. É } \\
\text { imprescindível que se evite a rigidez hierárquica (quando imposta pela IES) } \\
\text { afim de que cada especialista seja livre na expressão de suas opiniões. }\end{array}$ \\
\hline $5^{\mathbf{a}}$ Etapa & $\begin{array}{c}\text { Análise e } \\
\text { apresentação } \\
\text { consolidada dos } \\
\text { dados }\end{array}$ & $\begin{array}{l}\text { Considerar os dados previamente analisados e considerados comuns e } \\
\text { passíveis de generalizações no conjunto do projeto comum. Não há } \\
\text { atribuições para este ou aquele pesquisador, o resultado do projeto exige um } \\
\text { anonimato das integrantes do grupo. }\end{array}$ \\
\hline
\end{tabular}

Fonte: elaborado a partir de Japiassu (1976)

A partir da reflexão sobre os tópicos e métodos propostos por Japiasssu (1976) para ensino interdisciplinar foram estabelecidas as etapas a serem contempladas em cada um dos quatro pilares propostos por Kilpatrick (1929) e apresentados no trabalho de Leite (2007):

(1) Estabelecimento de propósito: buscou-se nesta fase estabelecer as disciplinas envolvidas no projeto, alinhamento de linguagem e metodologia, bem como o estabelecimento dos objetivos a serem alcançados.

(2) Planejamento do projeto: as etapas propostas nesta fase foram elaboradas objetivando atender aos dois níveis de projeto interdisciplinar apresentado por Japiassu (1976), a Démarche Pluridisciplinar e a Pesquisa Interdisciplinar. O enfoque do método nesta fase é a construção de uma proposta que atenda ao nível prospectivo, em que se busca a ordem prática. Esta etapa deve resultar no escopo do projeto.

(3) Execução: é neste pilar que se percebe a aplicação do escopo do projeto para o desenvolvimento do produto final, a partir do que Japiassu (1976) como nível prospectivo. 
(4) Julgamento/feedback: constitui-se como o nível retrospectivo do método proposto por Japiassu (1976), cujo enfoque está na reflexão sobre o projeto pelos envolvidos. As etapas estabelecidas para esta fase preveem uma avaliação dos trabalhos realizados pelo aluno, da execução do projeto e da atuação dos docentes. Busca-se assim, um aprimoramento contínuo do processo.

A partir desse entendimento teórico elaborou-se a proposta do processo de ensino de empreendedorismo por projeto interdisciplinar, que pode ser observado na Figura 1. Essa proposta foi, então, conforme já apresentada na seção 2, discutida com docentes e aprimorada, como pode ser observada na Figura 2.

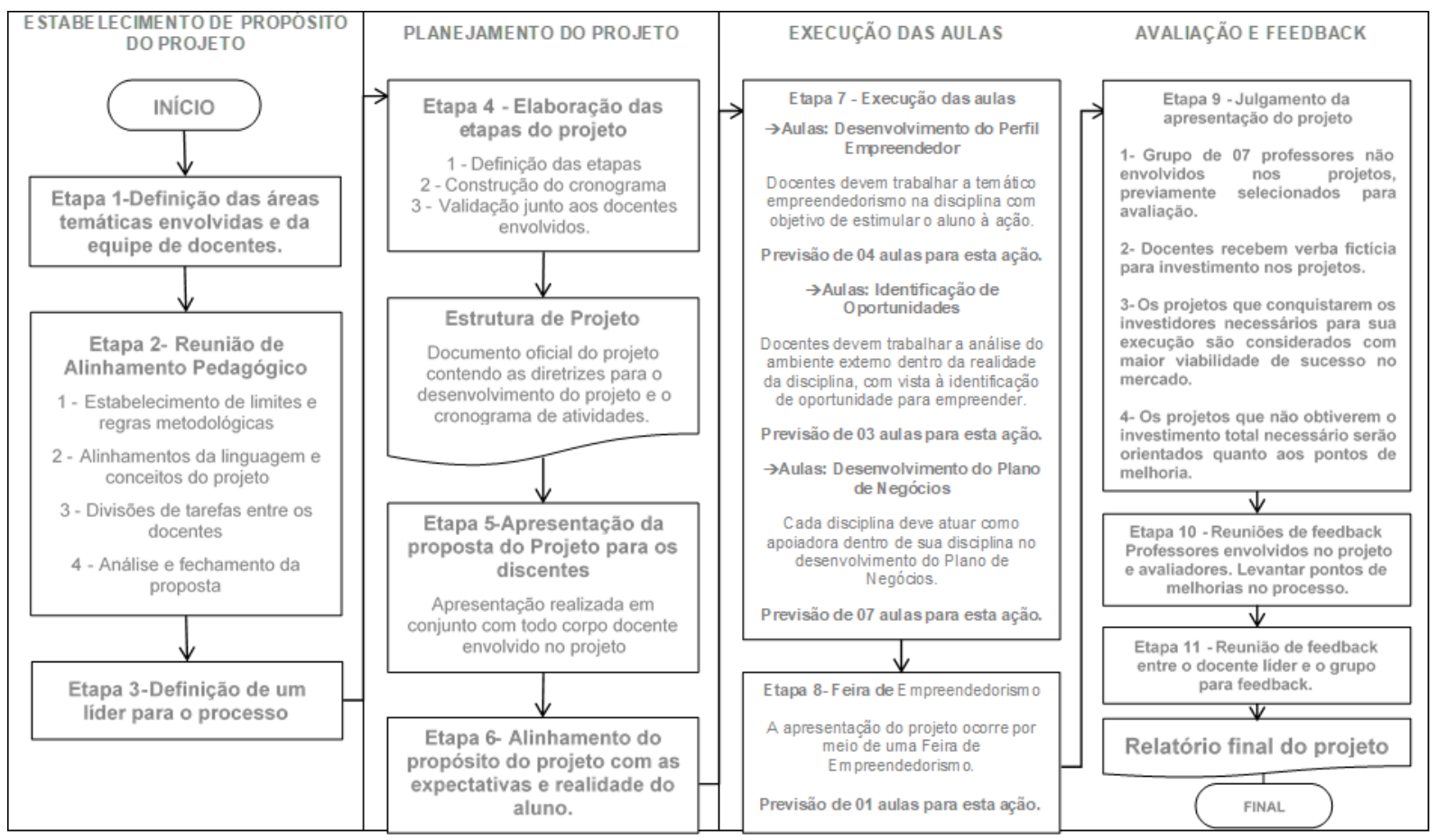

Figura 1: Proposta inicial do processo para ensino de empreendedorismo por projeto interdisciplinar

\section{Resultados obtidos com a pesquisa de campo}

Foram entrevistados doze docentes, com perfil variado, conforme pode ser visualizado no Quadro 2. Em sua maioria eram mestres, da área de administração, sendo que todos possuíam mais de dez anos de docência na temática.

Quadro 2: Perfil dos Entrevistados.

\begin{tabular}{|c|c|c|c|c|}
\hline Nome & Sexo & Título & Área & Tempo de Docência \\
\hline Especialista 01 & Masculino & Mestre & Administração & 15 anos \\
\hline
\end{tabular}




\begin{tabular}{|c|c|c|c|c|} 
Especialista 02 & Masculino & Especialista & Marketing & 10 anos \\
\hline Especialista 03 & Feminino & Mestre & Educação & 30 anos \\
\hline Especialista 04 & Feminino & Mestre & Educação & 20 anos \\
\hline Especialista 05 & Masculino & Mestre & Administração & 18 anos \\
\hline Especialista 06 & Masculino & Mestre & Administração & 23 anos \\
\hline Especialista 07 & Masculino & Mestre & Economia & 12 anos \\
\hline Especialista 08 & Masculino & Doutor & Administração & 27 anos \\
\hline Especialista 09 & Masculino & Especialista & Administração & 17 anos \\
\hline Especialista 10 & Masculino & Especialista & Marketing & 14 anos \\
\hline Especialista 11 & Feminino & Doutor & Comunicação & 32 anos \\
\hline Especialista 12 & Masculino & Mestre & Administração & 16 anos \\
\hline
\end{tabular}

Após a transcrição das entrevistas e respectiva análise, foram extraídas quinze unidades de registros: (i) Disciplinas envolvidas no ensino de empreendedorismo, (ii) Divisão de tarefas e responsabilidades, (iii) Liderança, (iv) Etapas de elaboração do projeto, (v) Relevância de um documento formal, (vi) Apresentação em conjunto aos discentes, (vii) Etapas de execução do projeto, (viii) Aulas destinadas a cada etapa, (ix) Adequação da proposta, (x) Sistema de Avaliação, (xi) Feedback entre docentes, (xii) Feedback dos alunos, (xiii) Relevância do documento final do projeto, (xiv) Arquivamento em repositório da faculdade e (xv) Viabilidade da proposta.

Percebeu-se pelas respostas dos respondentes que a disciplina de marketing é quase que unanimidade entre os entrevistados como uma das disciplinas primordiais de participação do projeto, talvez por sua associação entre empreendedorismo e mercado. Nos levantamentos feitos na pesquisa bibliográfica observou-se que o empreendedorismo surgiu a partir da influência de disciplinas tradicionais (LANDSTRÖM, HARIRCHI, ASTRÖM, 2012), o que pode demostrar uma maior proximidade dos entrevistados com determinadas disciplinas.

Consideraram ser primordial a divisão de tarefas e responsabilidades, o que corrobora com a afirmação de Fazenda (2002) sobre ser essencial tais questões em trabalhos interdisciplinares. Também mencionaram a importância de se ter um professor líder, aspecto mencionado por Japiassu (1976). Em concordância com Pombo (2006) os docentes entrevistados concordam que deve haver a integração das disciplinas em torno de um projeto e também encontros entre os docentes e discentes ao longo de todo o projeto. Os entrevistados relatam que o sistema propõe um ambiente que simula a realidade e esta característica contribuí com a proposta de projeto, promovendo aprendizagens significativas e concretas (TEROSSI; SANTANA, 2011).

As etapas foram construídas pensando na experiência prática a ser ofertada ao aluno e partindo de vivências em sala de aula (LOPES, 2010), o que se mostrou adequado no entendimento dos respondentes. O feedback também foi considerado essencial para a 
finalização do projeto proposto, corroborando com os pensamentos de Japiassu (1976) sobre colaboração e diálogo.

Por fim, todos os respondentes consideraram ser viável a proposta, sendo que a entrega do relatório final pode se transformar em um repositório para os futuros alunos, o que é bastante interessante para o aprendizado e para a instituição de ensino envolvida.

Com a pesquisa de campo percebeu-se que algumas alterações se faziam necessárias na proposta apresentada na Figura 1. Esses pontos foram tratados como os pontos de divergência da proposta inicial (Figura 1) e a proposta aprimorada pode ser observada na Figura 2.

Os principais pontos de divergência que suscitaram as alterações feitas na proposta inicial foram: (i) alteração no texto da etapa 4, (ii) fusão da etapa 5 e 6, (iii) inserção de uma ação de validação na etapa 6 , (iv) inserção de documento final revisado e aprovado (v) ampliação do número de aulas em algumas etapas, (vi) alteração na avaliação, (vii) alterada a reunião de feedback e (viii) alterado o tipo relatório final.

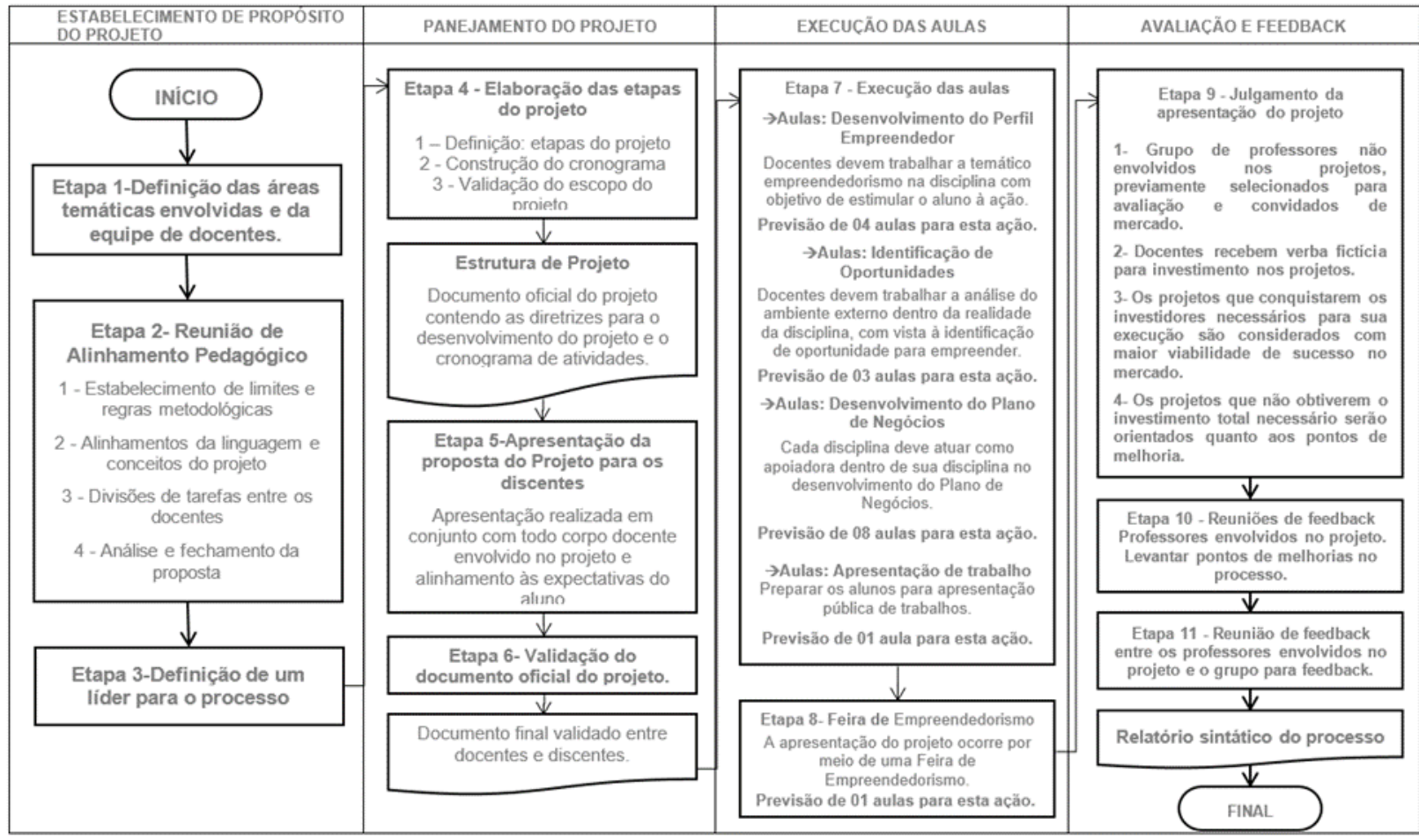

Figura 2: Proposta final do processo para ensino de empreendedorismo por projeto interdisciplinar

\section{Considerações finais}

A pesquisa contribui com as instituições de ensino superior e docentes que busquem modelos de ensino de empreendedorismo por uma perspectiva interdisciplinar. Instituições estas, preocupadas com uma formação de profissionais polivalentes e de visão holística, demanda cada vez maior do mercado. A elaboração de um processo, desenvolvido à luz da teoria e dos dados primários obtidos, mostra um dos caminhos possíveis para se ensinar 
empreendedorismo através de projetos interdisciplinares, respondendo a questão de pesquisa e alcançando o objetivo proposto na seção introdutória deste artigo. Apesar de ter se mostrado viável, a discussão sobre o processo proposto levantou algumas questões no que concerne vantagens e desvantagens, deixando alguns pontos não conclusivos para estudos futuros, situação essa característica de um estudo exploratório.

Algumas são, portanto, as vantagens percebidas com a possível utilização de projetos interdisciplinares no ensino de empreendedorismo: (1) propicia a troca de experiência entre os docentes; (2) promove maior integração entre o professor e o aluno; (3) estimula os alunos a ação; (4) estimula o compartilhamento do conhecimento entre todos os envolvidos; e (5) promove maior envolvimento do aluno com as aulas.

Como mencionado, também foram percebidas algumas desvantagens: (1) podem existir limitações de aplicação dada a matriz curricular dos cursos e política das instituições; (2) o processo demanda uma dedicação maior que a hora aula, o que pode ser um desafio para professores e instituições, em função do modelo de contratação da graduação; (3) o processo não é uma metodologia reconhecida, o que pode causar resistência natural por parte de alguns docentes; (4) o modelo por projeto pode confrontar com o modelo disciplinar se não for bem delineado; (5) o processo exige uma base de conhecimento por parte do aluno que limita a sua aplicação nos semestres iniciais; e (6) o modelo interdisciplinar pode exigir conhecimento do professor que não de sua área específica, visto ter que trabalhar em áreas subjacentes.

Apesar das desvantagens mencionadas, a maioria dos entrevistados salientou os benefícios proporcionados pela proposta apresentada e a viabilidade de se ensinar empreendedorismo através de um projeto interdisciplinar, ou mesmo integrador, que uma os conhecimentos de diferentes áreas do saber, proporcionando aos alunos um aprendizado prático e holístico.

Por esses pontos, pode-se sugerir estudos futuros: realização de experimentos de forma a testar a proposta do processo e aplicação da pesquisa pela perspectiva do aluno para verificação da percepção do discente sobre o processo e a sua contribuição para o aprendizado.

Como todo trabalho científico, o atual possui limitações de natureza metodológica e prática: a não aleatoriedade na seleção dos entrevistados pode ter causado viés uma vez que a mesma ocorreu por acessibilidade a partir de indicações de professores e coordenadores de cursos; apesar de se ter considerado a saturação dos dados para o encerramento da coleta de dados, foram entrevistados doze especialistas do estado de SP, o que não garante que representem a opinião de docentes de outros estados brasileiros; e, apesar de se ter utilizado a técnica projetiva, considera-se que pode ter havido vieses no que diz respeito à comunicação, dada a necessidade de explicar o processo ao entrevistado.

Acredita-se que o processo proposto nesta pesquisa pode ser aplicado por docentes que percebam vantagens ao utilizar projetos interdisciplinares para se ensinar empreendedorismo, amparados pelas instituições de ensino que queiram incluir em sua grade curricular projetos integradores e que vislumbrem a prática como essência do aprendizado de determinadas temáticas, como empreendedorismo.

\section{Referências}

BARDIN, Laurence. Análise de conteúdo. Lisboa: Editora Edições, 2009.

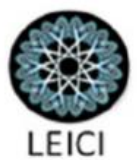


BEHRENS, M. A. B. Paradigma da Complexidade. Metodologia de projetos, contratos didáticos e portfólios. Petrópolis. Vozes. 2006.

CATTAI, M. D. S.; PENTEADO, M. G. A formação do professor de matemática e o trabalho com projetos na escola. Ciência \& Educação, v. 15, n. 1, p. 105-20, 2009.

CIOBOTARU, A.C. Entrepreneurial education as a society project. An essay on the conceptualization of the spirit of initiative and entrepreuneurship in educational field. Review of Economic Studies and Research Virgil Madgearu, v. 6, n. 1, p. 41, 2013.

CRESWELL, J. W. Projeto de Pesquisa: Métodos qualitativo, quantitativo e misto. 2. ed. Porto Alegre: Artmed, 2010.

CRONIN, P.; RYAN, F.; COUGHLAN, M. Undertaking a literature review: a step-by-step approach. British Journal of Nursing, v. 17, n.1, p.38-43, 2008.

DENZIN, N. K. e LINCOLN, Y. S. Introdução: a disciplina e a prática da pesquisa qualitativa. In: DENZIN, N. K. e LINCOLN, Y. S. (Orgs.). O planejamento da pesquisa qualitativa: teorias e abordagens. 2. ed. Porto Alegre: Artmed, p. 15-41, 2006.

ENDEAVOR; SEBRAE. Empreendedorismo nas Universidades Brasileiras. 2014. Disponível em: https://endeavor.org.br/empreendedorismo-nas-universidades-2014/ Acesso em: $12 / 07 / 2017$

FAZENDA, I. C. A. Interdisciplinaridade: um projeto em parceria. Edições Loyola, 1991.

FAZENDA, I. C. A. Integração e interdiciplinaridade no ensino superior brasileiro. Edições Loyola, 2002.

FILION, Louis Jacques. Empreendedorismo: empreendedores e proprietários-gerentes de pequenos negócios. Revista de Administração, v. 34, n. 2, p. 5-28, 1999.

FLICK, W. Introdução à pesquisa qualitativa. Tradução Joice Elias Costa. 3. Ed. Porto Alegre: Artmed, 2009.

GARCIA, J. O futuro das práticas de interdisciplinaridade na escola. Revista Diálogo Educacional, Curitiba, v.12, n.35, p.211 - 232, 2012.

GIL, A. C. Métodos e técnicas de pesquisa social. São Paulo: Atlas, 2010.

JAPIASSU, H. Interdisciplinaridade e patologia do saber. Imago Editora, 1976. 
KATZ, J. A. The chronology and intellectual trajectory of American entrepreneurship education: 1876-1999. Journal of business venturing, v. 18, n. 2, p. 283-300, 2003.

KILPATRICK, W. H. The project method: The use of the purposeful act in the educative process. 11a. ed. Columbia University, New York, 1929.

KRAKAUER, P. V. C. Empreendedorismo como disciplina: mapeamento das ideias fundamentais. Relatório de pós-doutorado. Faculdade de Educação da Universidade de São Paulo. USP, São Paulo, 2016, 166 p.

LANDSTRÖM, H.; HARIRCHI, G.; ÅSTRÖM, F. Entrepreneurship: Exploring the knowledge base. Research Policy, v. 41, n. 7, p. 1154-1181, 2012.

LAVIERI, Carlos. Educação... empreendedora? In: LOPES, Rose Mary A. (Org.). Educação empreendedora: conceitos, modelos e práticas. Rio de Janeiro: Elsevier; São Paulo: Sebrae, 2010.

LEITE, A. C. C. A. A noção de projeto na educação: o "método de projeto" de William Heard Kilpatrick. 2007. 72 f. Dissertação (Mestrado em Educação) - Pontifícia Universidade Católica de São Paulo, São Paulo, 2007.

LOPES, R. M. A. Educação empreendedora: conceitos, modelos e práticas. Elsevier, 2010.

MORAES, L. V. S; HOELTGEBAUM, M. Um modelo para a análise do processo de aprendizagem de empreendedores. In: 3rd. International Conference of the Ibero American Academy of Management, São Paulo, 2003. Anais...

MORIN, E; LE MOIGNE, J. A inteligência da complexidade. Tradução de Nurimar Maria Falci, São Paulo: Peirópolis, 2000.

MORIN, E. Desafios da transdisciplinaridade e da complexidade. Inovação e interdisciplinaridade na universidade. Porto Alegre: EDIPUCRS, 2007.

NECK, H.; GREENE, P. Entrepreneurship education: known worlds and new frontiers. Journal of Small Busines Management, v.49, n.1, p.55-70, 2011. doi: 10.1111/j.1540627X.2010.00314.X

POLITIS, D. The process of entrepreneurial learning: a conceptual framework. Entrepreneurship Theory and Pratice, v. 29, issue 4, p. 399-424, July, 2005.

POMBO, O. Práticas interdisciplinares. Sociologia, v.8, n.15, p. 208-249, jan-jun 2006. Disponível em: http://www.seer.ufrgs.br/sociologias/article/view/5570

Acessado em 15.11.2016 
PRODANOV, C. C.; DE FREITAS, Ernani Cesar. Metodologia do Trabalho Científico: Métodos e Técnicas da Pesquisa e do Trabalho Acadêmico-2a Edição. Editora Feevale, 2013.

RAE, D. Entrepreneurial learning: a practical model from the creative industries. Education \& Training, v. 46, n 8/9, p. 492-500, 2004.

SILVA, F. A. G.; RIBEIRO, R. C. L.; PINTO, F. R.; OLIVEIRA, L. G. L. Projeto Arquimedes: empreendedorismo nas Instituições de Ensino superior Superior. Revista Pretexto, v. 10, n. 4, art. 2, p. 31-48, 2009.

TEROSSI, M. J.; SANTANA, L. C. Projetos: Alternativas viáveis na Educação Ambiental?. Educação: Teoria e Prática, v. 21, n. 37, p. 135-154, 2011. Disponível em: http://hdl.handle.net/11449/106866

Acessado em 20.12.2016.

SALUSSE, M. A. Y.; ANDREASSI, T. O ensino superior de empreendedorismo com fundamento na teoria effectuation. RAC-Revista de Administração Contemporânea, v. 20, n. 3, p. 305-327, 2016.

SARASVATHY, S. D.; VENKATARAMAN, S. Entrepreneurship as method: open questions for an entrepreneurial future. Entrepreneurship Theory and Practice, v.35, n.1, p.113-135, 2011. doi:10.1111/j.1540-6520.2010.00425.x

VANEVENHOVEN, J. Advances and challenges in entrepreneurship education. Journal of Small Business Management, v. 51, n. 3, p. 466-470, 2013.

VIDAL, D. G. Escola nova e processo educativo. LOPES, Eliane Marta Teixeira; FARIA FILHO, Luciano Mendes; VEIGA, Cynthia Greive, v. 500, p. 497-517, 2000.

WRIGHT, J. T. C.; SILVA, A. T. B.; SPERS, R. G. O mercado de trabalho no futuro: uma discussão sobre profissões inovadoras, empreendedorismo e tendências para 2020. RAI Revista de Administração e Inovação, São Paulo, v. 7, n. 3, p. 174-197, nov. 2010. doi:10.5585/rai.2010505.

ZAMPIER, M. A.; TAKAHASHI, A. R. W. Competências empreendedoras e processos de aprendizagem empreendedora: modelo conceitual de pesquisa. Cadernos Ebape. BR, p. 564$585,2011$. 